\title{
Rancang Bangun Sistem Overhead Chain Conveyor untuk Pengeringan Gitar dengan Penggerak Motor Listrik 1 HP
}

\author{
Suharto $^{1}$, Sarana ${ }^{2}$, Ahmad Khilmi Hidayat ${ }^{1}$, Febrya Yoga Pratama ${ }^{1}$, Mahdelia Fa'iq Alamsyah ${ }^{1}$, \\ Yanuar Ilham Ramadhan', Eko Saputra ${ }^{1^{*}}$ \\ ${ }^{1}$ Jurusan Teknik Mesin, Politeknik Negeri Semarang \\ ${ }^{2}$ Jurusan Akuntansi, Politeknik Negeri Semarang \\ Jl. Prof. H. Soedarto S.H., Tembalang, Semarang 50275, Telp. +62247473417 \\ *E-mail: eko.saputra@polines.ac.id
}

Diterima: 15-10-2021; Direvisi: 14-11-2021; Dipublikasi: 30-12-2021

\begin{abstract}
Abstrak
Proses pengeringan gitar pada produksi gitar di Usaha Mikro Kecil Menengah (UMKM) masih menggunakan cara manual seperti mengeringkan di luar ruangan, hal ini tentu akan memperlambat proses produksi karena masih mengandallkan bantuan sinar matahari dan udara. Proses pengeringan gitar yang baik memiliki peran penting khususnya dari segi estetika dalam pembuatan gitar. Kualitas permukaan gitar diharapkan memiliki tingkat kehalusan yang baik dan tanpa debu. Oleh karena itu, metode pengeringan gitar yang baik sangat diperlukan oleh UMKM. Tujuan penelitian ini adalah merancang dan menganalisa sistem overhead chain conveyor untuk pengeringan gitar dengan penggerak motor listrik $1 \mathrm{HP}$. Penelitian ini dilakukan untuk menangani permasalahan pengeringan gitar agar efektif dan meminimalisir adanya debu pada permukaan gitar. Alat bantu pengeringan gitar ini menggunakan kendali forward reverse untuk sistem kendalinya dengan penggerak motor induksi. Pada hasil, analisa dan evaluasi dilakukan dengan pengujian terhadap efisien waktu proses pengeringan gitar. Pada penelitian ini, diperoleh waktu pengeringan tercepat pada 40 menit. Hal ini mampu memangkas waktu 15 menit dari metode pengeringan yang ada sebelumnya. Cepatnya waktu pengeringan ini tentu akan mendorong produktivitas pada UMKM.
\end{abstract}

Kata kunci: Overhead chain conveyor; pengeringan gitar; forward-reverse

\begin{abstract}
The guitar drying process in guitar production in Micro, Small and Medium Enterprises (MSMEs) still uses manual methods such as drying outdoors, this will certainly slow down the production process because it still relies on the help of sunlight and air. A good guitar drying process has an important role, especially in terms of aesthetics in guitar making. The surface quality of the guitar is expected to have a good level of smoothness and without dust. Therefore, a good guitar drying method is needed by SMEs. The purpose of this study was to design and analyze an overhead chain conveyor system for guitar drying with a 1 HP electric motor drive. This research was conducted to deal with the problem of drying the guitar to be effective and to minimize the presence of dust on the surface of the guitar. This guitar drying tool uses forward reverse control for its control system with an induction motor drive. In the results, analysis and evaluation were carried out by testing the time efficiency of the guitar drying process. In this study, the fastest drying time was obtained at 40 minutes. This is able to cut 15 minutes of drying time from the previous drying method. This fast drying time will certainly encourage productivity in MSMEs.
\end{abstract}

Keywords: Overhead chain conveyor; pengeringan gitar; forward-reverse

\section{Pendahuluan}

Kecamatan Baki, kabupaten Sukoharjo terkenal sebagai sentra industri kerajinan gitar sejak puluhan tahun yang lalu. Pencanangan wilayah usaha sentra gitar telah ditetapkan Pemerintah Daerah tahun 2006 dengan pemasangan papan nama di jalan masuk desa. Kecamatan Baki adalah salah satu kecamatan di Kabupaten Sukoharjo Provinsi Jawa Tengah penduduknya banyak yang bekerja sebagai pengrajin gitar. Seperti Desa Mancasan, Kecamatan Baki, telah lama dikenal sebagai daerah industri rumah gitar [1,2]. Sejak tahun 1975, para penduduk desa tersebut telah mulai merintis usaha pembuatan gitar. Semakin lama banyak perajin yang ikut membuat gitar dan lambat laun daerah ini terkenal sebagai sentra pembuatan gitar. Pesatnya industri gitar di Desa Mancasan berdampak pada desa sekitar, salah satu diantaranya adalah Desa Ngrombo. Sentra gitar Baki dikenal berkualitas baik, dan selalu mendapat pesanan dari berbagai toko alat musik di 
Suharto dkk./Jurnal Rekayasa Mesin p-ISSN: 1411-6863, e-ISSN: 2540-7678

Vol.16|No.3|425-436|Desember|2021

sejumlah kota seperti Surakarta, Yogyakarta, Surabaya, Bandung dan Jakarta. Bahkan gitar produksi Desa Mancasan dan Desa Ngrombo mampu menembus pasaran mancanegara meskipun masih melalui pihak ketiga. Pencanangan kedua desa ini sebagai sentra kerajinan gitar ditunjukkan dalam papan yang berada di gerbang desa.

Identifikasi permasalahan UMKM dengan pemilik usaha gitar di Desa Ngrombo, Kecamatan Baki, Kabupaten Sukoharjo mempunyai keterbatasan sumber daya. Sumber daya manusia (SDM) yang terampil, teknologi produksi, dan pemodalan. Teknologi produksi diperlukan untuk meningkatkan mutu dan jumlah produksi gitar. Proses finishing pengeringan gitar setelah dicat mengalami penanganan yang kurang maksimal. Dibuktikan dengan proses pengeringan gitar dikeringkan dengan cara manual diletakkan dilantai sehingga gitar yang sudah dicat sering kali terkena kotoran atau debu yang mengakibatkan nilai tambah dalam segi estetika berkurang, seperti pada Gambar 1.

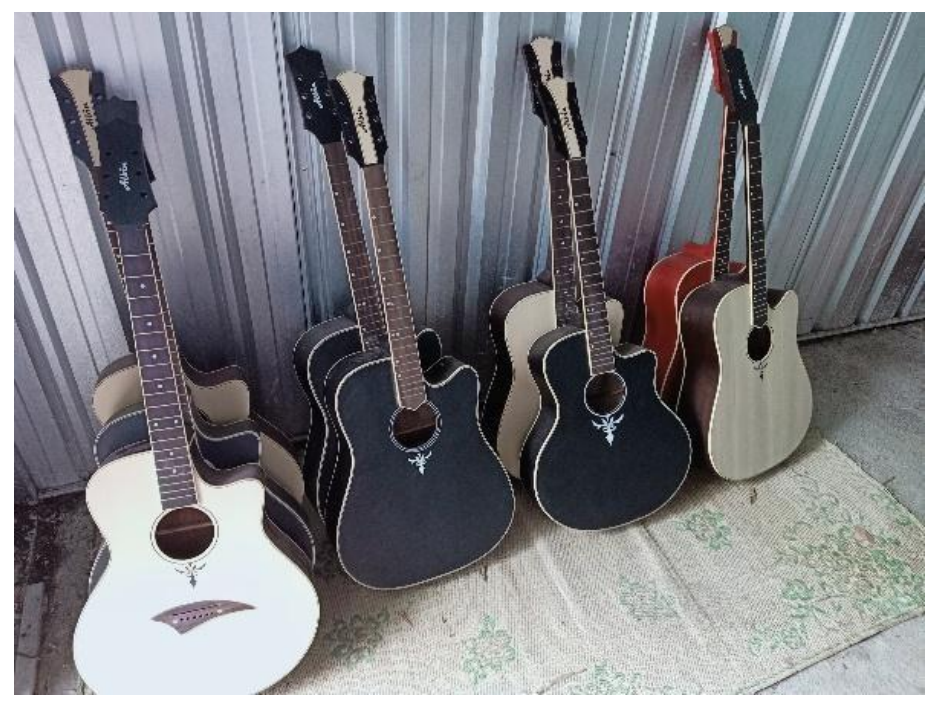

Gambar 1. Proses pengeringan Manual

Selain hal itu, hasil akhir dari pengeringan berupa kehalusan permukaan gitar tidak merata dan waktu pengeringan yang cukup lama dengan memakan waktu satu jam setiap tahapan proses pengecatan. Hal ini tentu menjadi salah satu penghambat pada proses produksi gitar di UMK. Dengan permasalahan tersebut, maka alat bantu proses pengeringan gitar yang lebih efisien sangat diperlukan. Tujuan penelitian ini adalah merancang dan menganalisa Sistem Overhead Chain Conveyor untuk Pengeringan Gitar dengan Penggerak Motor Listrik 1 HP.

\section{Tahap Perancangan Alat Pengeringan Gitar}

Tahapan perancangan (design) memiliki tujuan untuk mendesain sistem baru yang dapat menyelesaikan masalahmasalah yang dihadapi perusahaan yang diperoleh dari pemilihan alternatif sistem yang terbaik. [3]. Dalam merancang overhead chain conveyor memerlukan desain yang proposional dan sesuai kriteria yang digunakan. Berikut langkahlangkah pembuatan mesin dari awal sampai akhir pembuatan (Gambar 2).

Pada tahap identifikasi kebutuhan, pertama membuat pernyataan lengkap mengenai masalah, menunjukan kebutuhan, maksud atau tujuan mesin yang dirancang [4]. Proses pengeringan gitar masih menggunakan proses manual yaitu dengan menggantungkan gitar secara manual pada sebuah gantungan yang ada pada sebuah ruang pemanas. Untuk itu diperlukan alternatif dalam menggantung gitar yaitu dengan overhead chain conveyor yang dapat memudahan operator untuk menggantungkan gitar dan juga membuat proses pengeringan gitar lebih efektif. Definisi masalah bersifat spesifik 
Suharto dkk./Jurnal Rekayasa Mesin p-ISSN: 1411-6863, e-ISSN: 2540-7678

Vol.16|No.3|425-436|Desember|2021

dan harus mencakup semua spesifikasi meliputi input dan output jumlah, karakteristik, dimensi ruang yang harus ditempati objek, serta batasan jumlah [4]. Pada definisi masalah ini penulis mendefinisikan masalah mengenai sistem overhead chain conveyor yang akan digunakan. Perancangan mesin yang akan digunakan yaitu menentukan daya motor listrik, kebutuhan desain, kelebihan dan kelemahan rancangan, fungsi dan sebagainya.

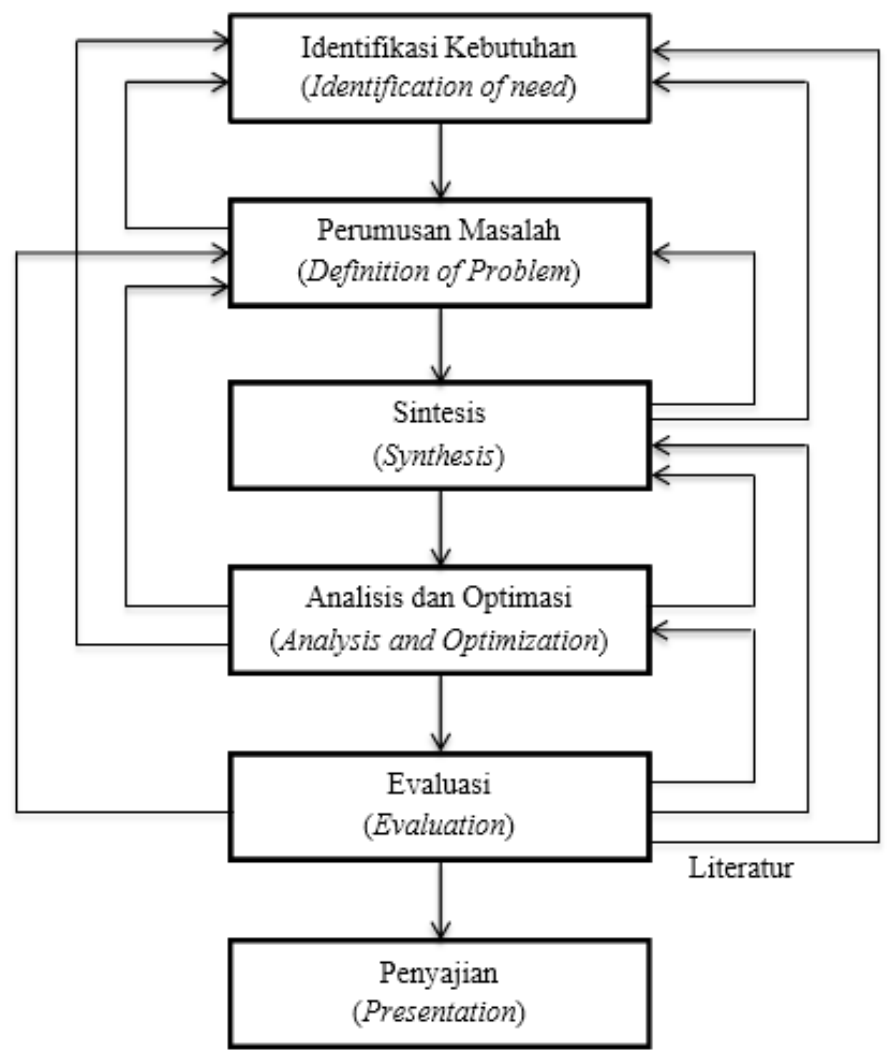

Gambar 2. Diagram Alir Proses Perancangan [4]

Tahap sintesis merupakan tahap untuk menemukan konsep atau desain konsep. Berbagai skema harus diusulkan, diselidiki, dikuantifikasi dan dianalisis untuk menilai apakah kinerja sistem memuaskan atau lebih baik, dan jika memuaskan, seberapa baik kinerjanya [4]. Berdasarkan definisi masalah yang ada, maka diperlukan alternatif desain untuk menentukan desain mesin yang ada akan dibuat berdasarkan pertimbangan mesin serta sistem penilaian antara alternatif desain 1, alternatif desain 2 dan alternatif desain 3. Beberapa alternatif konsep produk pada tahap sintesis kemudian dipilih untuk dianalisis lebih lanjut. Analisis ini meliputi analisis gaya, tegangan, deformasi, getaran, dan lainlain [5]. Pada tahap ini dilakukan analisa perhitungan terhadap sistem overhead chain conveyor berdasarkan perhitungan gaya, tegangan, torsi, kapasitas dan lainnya.

Tahap evaluasi merupakan bukti akhir dari sebuah kesuksesan desain dan biasanya melibatkan pengujian di laboratorium untuk mengetahui apakah desain mampu memenuhi kebutuhan dan dapat diandalkan [4]. Pada proses ini dilakukan pengujian sistem overhead chain conveyor dan mengevaluasi kinerja model tersebut sehingga dapat memenuhi kebutuhan dan dapat diandalkan. Tahap terakhir dalam proses perancangan adalah presentasi, yaitu mengkomunikasikan desain konsep kepada orang lain [4]. Tahap presentasi ini menyusun dokumen hasil perancangan sistem overhead chain conveyor berupa gambar kerja, daftar komponen, spesifikasi bahan dan informasi lainnya. 
Suharto dkk./Jurnal Rekayasa Mesin p-ISSN: 1411-6863, e-ISSN: 2540-7678

Vol.16|No.3|425-436|Desember|2021

\section{Hasil dan pembahasan}

\subsection{Model Pengering Gitar}

Tahap untuk menentukan desain yang terbaik, maka diperlukan beberapa alternatif desain untuk sistem overhead chain conveyor dimana alternatif desain ini memiliki kelebihan dan kelemahan yang akan dinilai dari masing-masing alternatif desain. Semua perancangan, perencanaan dan pemilihan elemen mesin yang digunakan dengan mempertimbangkan literature $[4,5,6,7,8]$. Pada topik ini penulis memiliki 3 alternatif desain yaitu :

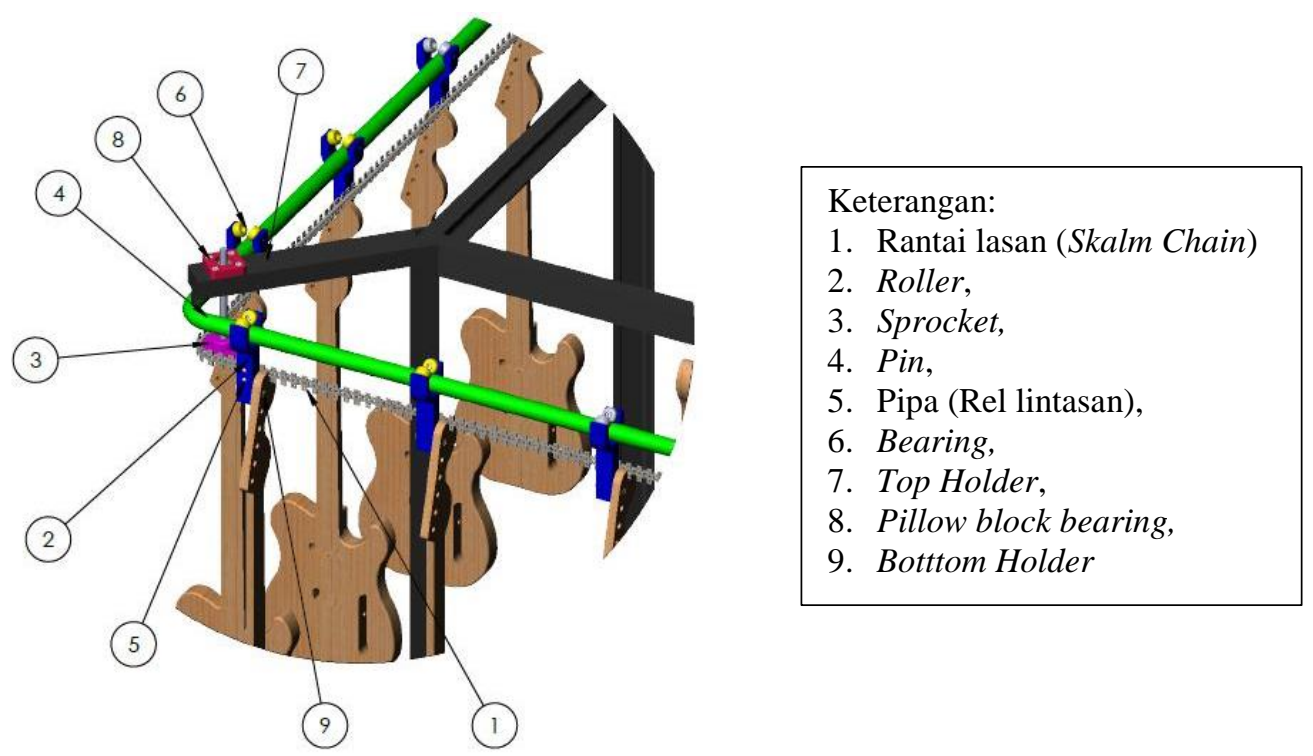

Gambar 3. Alternatif desain 1

Pada alternatif desain 1 (Gambar 3) sistem pengikatan menggunakan rantai diikat dengan komponen berupa pin untuk menarik masing-masing holder dengan bantuan kontak antara sprocket penggerak dan rantai serta pin untuk menjadikan gerakan secara serentak dan paten. Metode ini juga sudah banyak digunakan pada pekerjaan orang lain [9, 10]. Desain ini juga menggunakan bearing dan pillow block bearing sebagai pendukung putaran motor agar dapat berputar dengan lancer [11]. Pada pemasangan workpiece (gitar) tergolong mudah dan cepat, yaitu pengikatan baja beton pada Bottom holder dan lubang pada stang gitar. Terlepas dari itu, pada pengikatan Top Holder dan bottom holder dengan bantuan Pin untuk pengikatan antara keduanya.

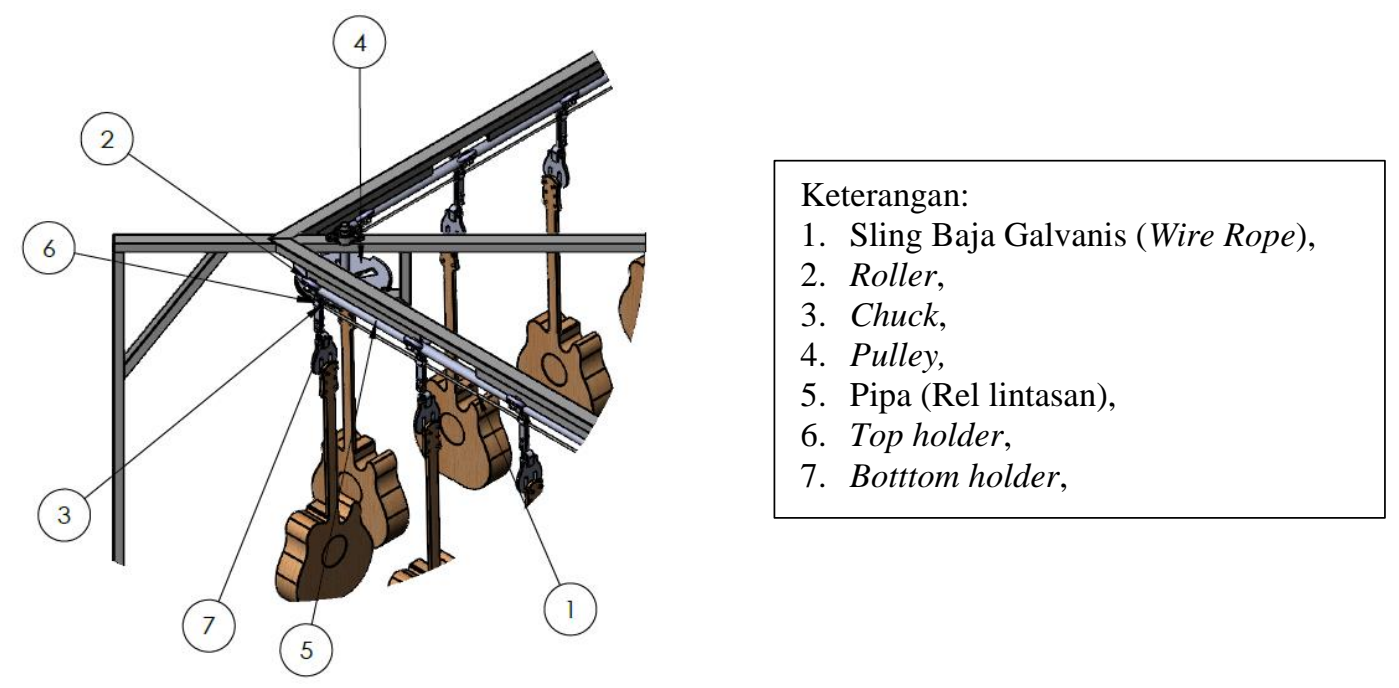

Gambar 4. Alternatif desain 2 
Suharto dkk./Jurnal Rekayasa Mesin p-ISSN: 1411-6863, e-ISSN: 2540-7678

Vol.16|No.3|425-436|Desember|2021

Pada alternatif desain 2 (Gambar 4) sistem pengikatan menggunakan sling baja (wire rope) dengan pelapisan galvanis yang diikat dengan komponen berupa chuck untuk menarik masing-masing holder dengan bantuan kontak antara pulley penggerak dan chuck untuk menjadikan gerakan secara serentak dan paten. Pada pemasangan workpiece (gitar) tergolong mudah dan cepat, yaitu pengikatan baja beton pada Bottom holder dan lubang pada stang gitar. Terlepas dari itu, pada pengikatan Top Holder dan bottom holder dengan bantuan Pin untuk pengikatan antara keduanya.

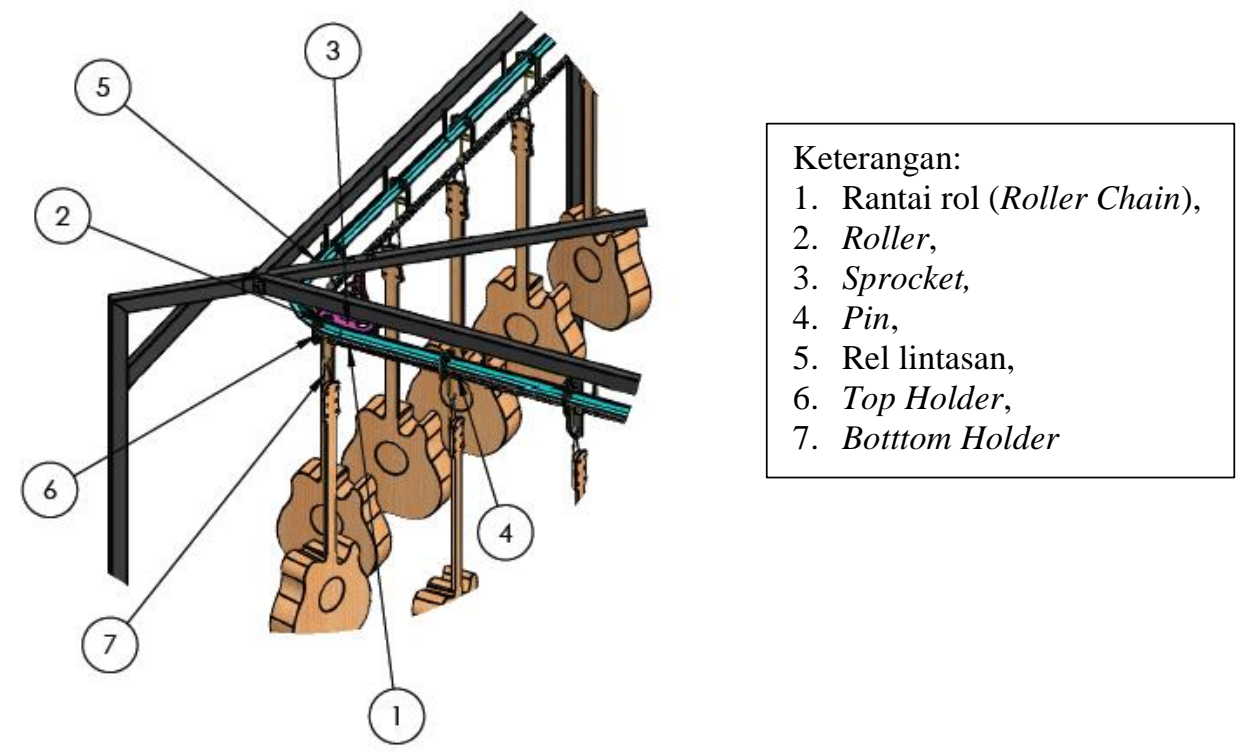

Gambar 5. Alternatif desain 3

Pada alternatif desain 3 (Gambar 5) sistem pengikatan menggunakan rantai diikat dengan komponen berupa pin untuk menarik masing-masing holder dengan bantuan kontak antara sprocket penggerak dan rantai serta pin untuk menjadikan gerakan secara serentak dan paten. Pada pemasangan workpiece (gitar) tergolong mudah dan cepat, yaitu pengikatan baja beton pada Bottom holder dan lubang pada stang gitar. Terlepas dari itu, pada pengikatan Top Holder dan bottom holder dengan bantuan Pin untuk pengikatan antara keduanya. Berdasarkan penilaian, menunjukkan bahwa desain 3 memiliki keunggulan dibandingkan desain 1 dan 2. Maka dari itu, desain 3 digunakan acuan dalam pembuatan alat pengering gitar pada penelitian ini. Alat bantu pengeringan gitar dengan mekanisme overhead chain conveyor untuk menangani efektivitas waktu pengeringan gitar, lihat Gambar 6.

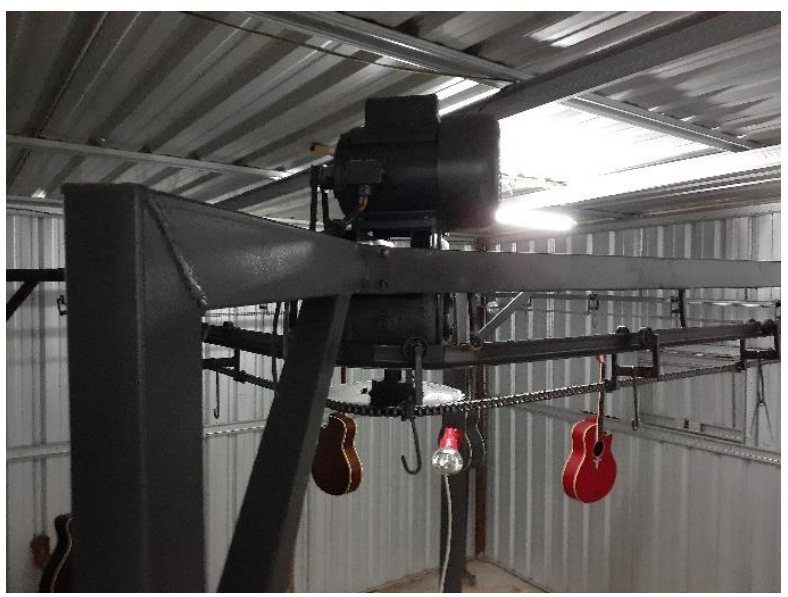

Keterangan:

1. Panjang Rangka: 3870 [mm]

2. Lebar Rangka: 3870 [mm]

3. Tinggi Rangka: 2400 [mm]

4. Lebar lintasan: 2770 [mm]

5. Jumlah Sprocket: 4 [piece]

6. Kec. rantai: $0,3[\mathrm{~m} / \mathrm{s}]$

7. Daya penggerak: 1 HP Single Phase

8. Daya Tampung: 20 [Unit]

9. Sistem Kontrol: Forward-Reverse

Gambar 6. Model sistem overhead chain conveyor untuk pengeringan gitar dengan penggerak motor listrik 1HP 
Suharto dkk./Jurnal Rekayasa Mesin

p-ISSN: 1411-6863, e-ISSN: 2540-7678

Vol.16|No.3|425-436|Desember|2021

\subsection{Kekuatan Rangka Pengering Gitar}

Berdasarkan analisa FEA pada software Solidwork, didapatkan 3 hasil yakni analisa tegangan (von Mises) pada rangka, analisa pergeseran struktur akibat beban yang diterima atau defleksi pada struktur material (displacement), dan analisa FOS (Factor of Safety) pada struktur rangka.

\subsubsection{Analisa tegangan pada struktur rangka}

Tegangan von Mises merupakan indikator yang mengukur kegagalan material dengan menganalisis resultan 3 tegangan utama atau biasa disebut Principal Stress, kegagalan diprediksi jika nilai tegangan von Mises lebih besar dari tegangan luluh material (sv > sy).

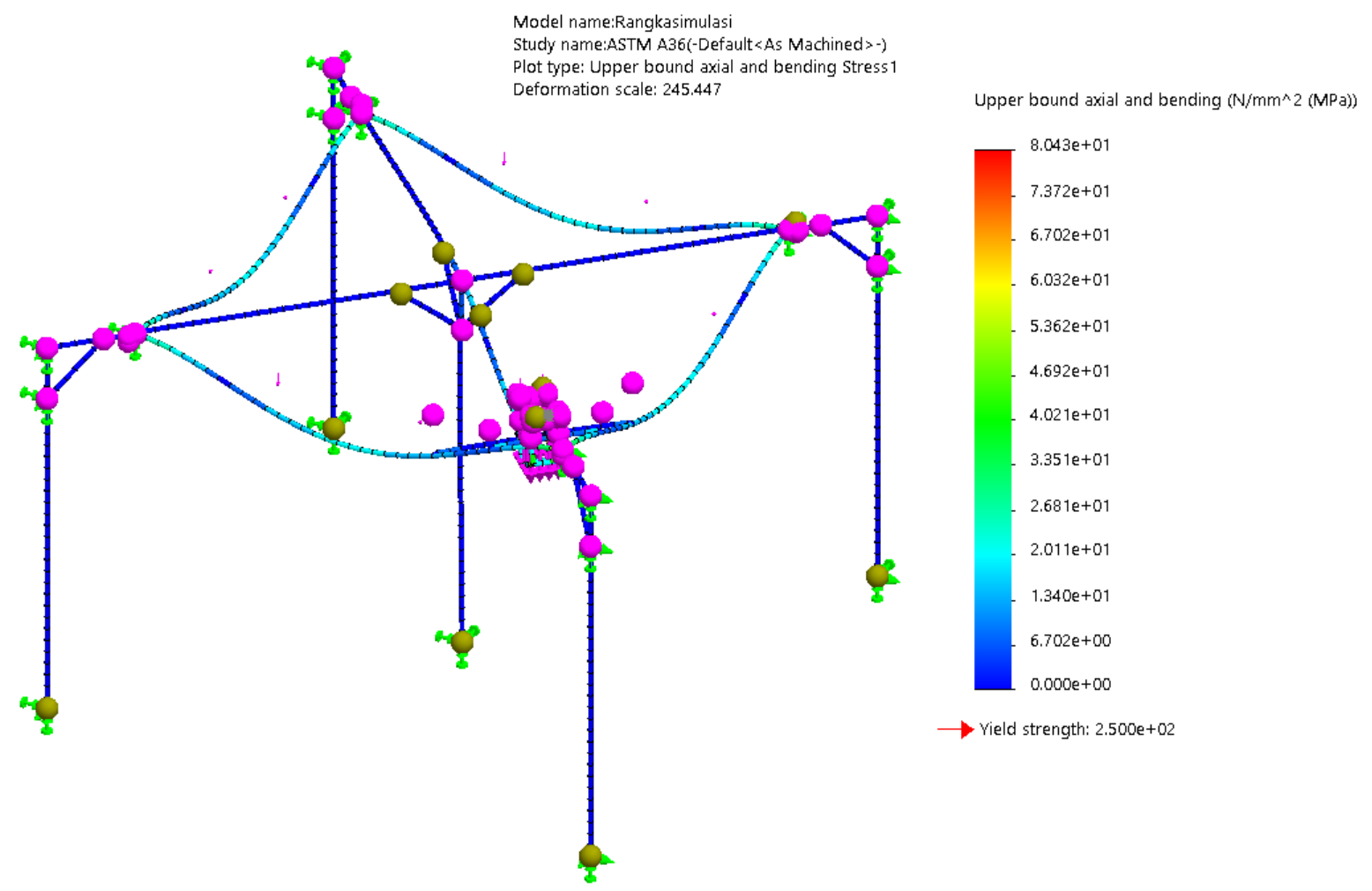

Gambar 7. Analisa Von Mises

Simulasi Gambar 7 pada dasarnya membandingkan antara tegangan luluh material rangka (Yield Strength) dan tegangan tarik yang terjadi, 250 (N/mm atau MPa) untuk tegangan Yield Strength bahan ASTM A36 dan tegangan yang terjadi pada bahan material rangka dengan beban tumpu terbesar pada rel lintasan (Roller Guide Holder) diikuti gaya berat pada bracket reducer dan gaya berat motor listrik penggerak dengan jumlah total rata-rata rentang 201-206 (N/mm2 atau MPa) yang ditandai warna biru. Perbedaan ini bisa ditarik kesimpulan bahwa YS > VM, maka tegangan von mises yang dihasilkan masih AMAN dan kontruksi aman apabila dikenai beban yang ada.

\subsubsection{Analisa Defleksi struktur material atau momen bengkok pada struktur material}

Dari hasil simulasi (Gambar 8) bagian pergeseran material (displacement) didapatkan nilai defleksi sebesar 1,455 $\mathrm{mm}$ untuk nilai terbesarnya dengan ditadai warna merah defleksi paling besar ditandai dengan warna merah. Hal ini masih dikatakan aman jika dengan adanya defleksi terbesar pada material rangka tersebut pada prinsipnya tidak mengganggu fungsi dari mesin. 
Suharto dkk./Jurnal Rekayasa Mesin

p-ISSN: 1411-6863, e-ISSN: 2540-7678

Vol.16|No.3|425-436|Desember|2021

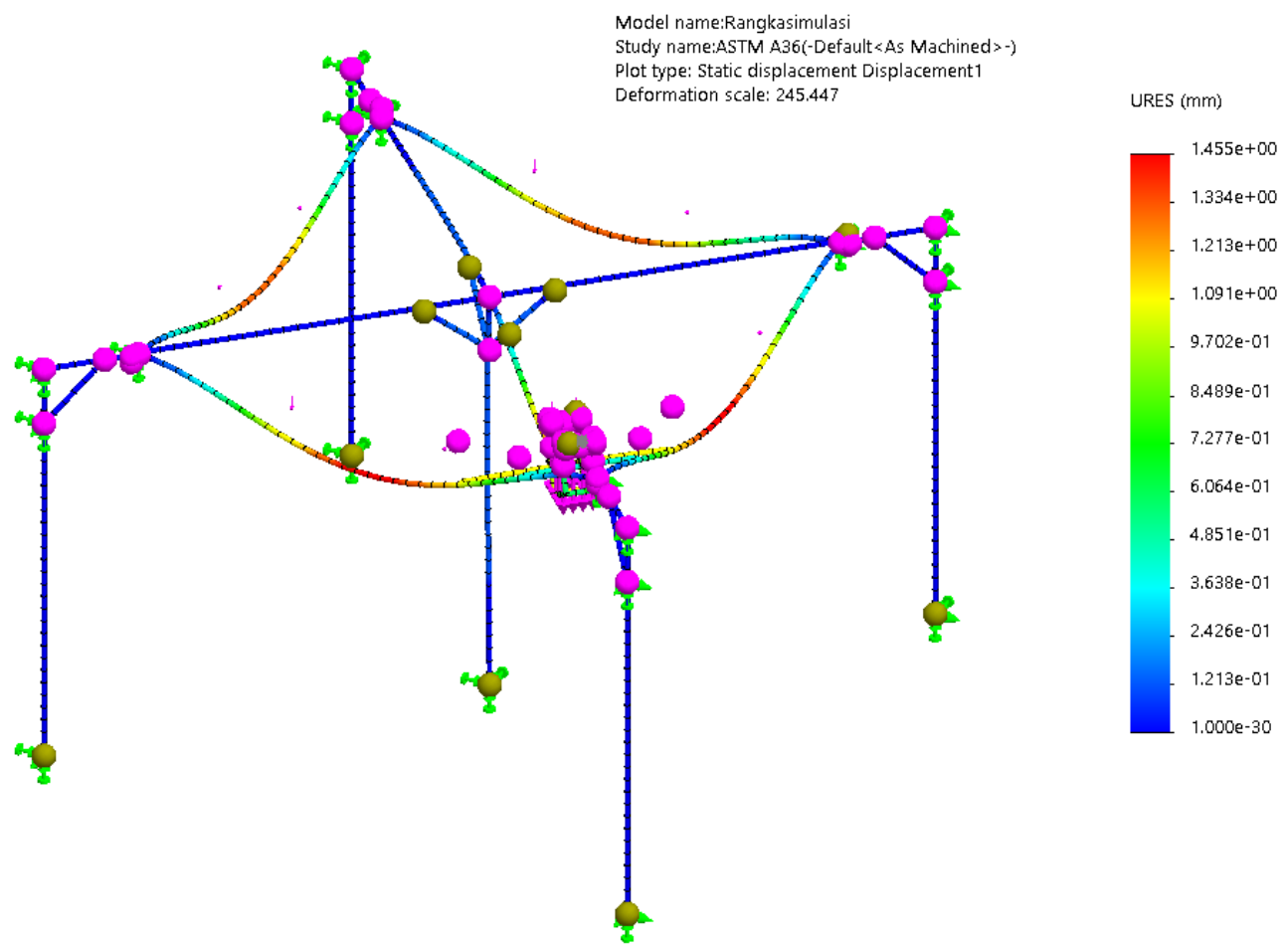

Gambar 8. Analisa Displacement

\subsubsection{Analisa FOS (Factor of Safety)}

Faktor keamanan menggunakan simulasi Software Solidwork dihitung sebagai kekuatan luluh (yield strength) dari material yang dibagi dengan tegangan von Mises maksimum dari material tersebut. Faktor keamanan yang dihitung ditunjukkan pada balok warna yang diikuti nilai minimum (Gambar 9).

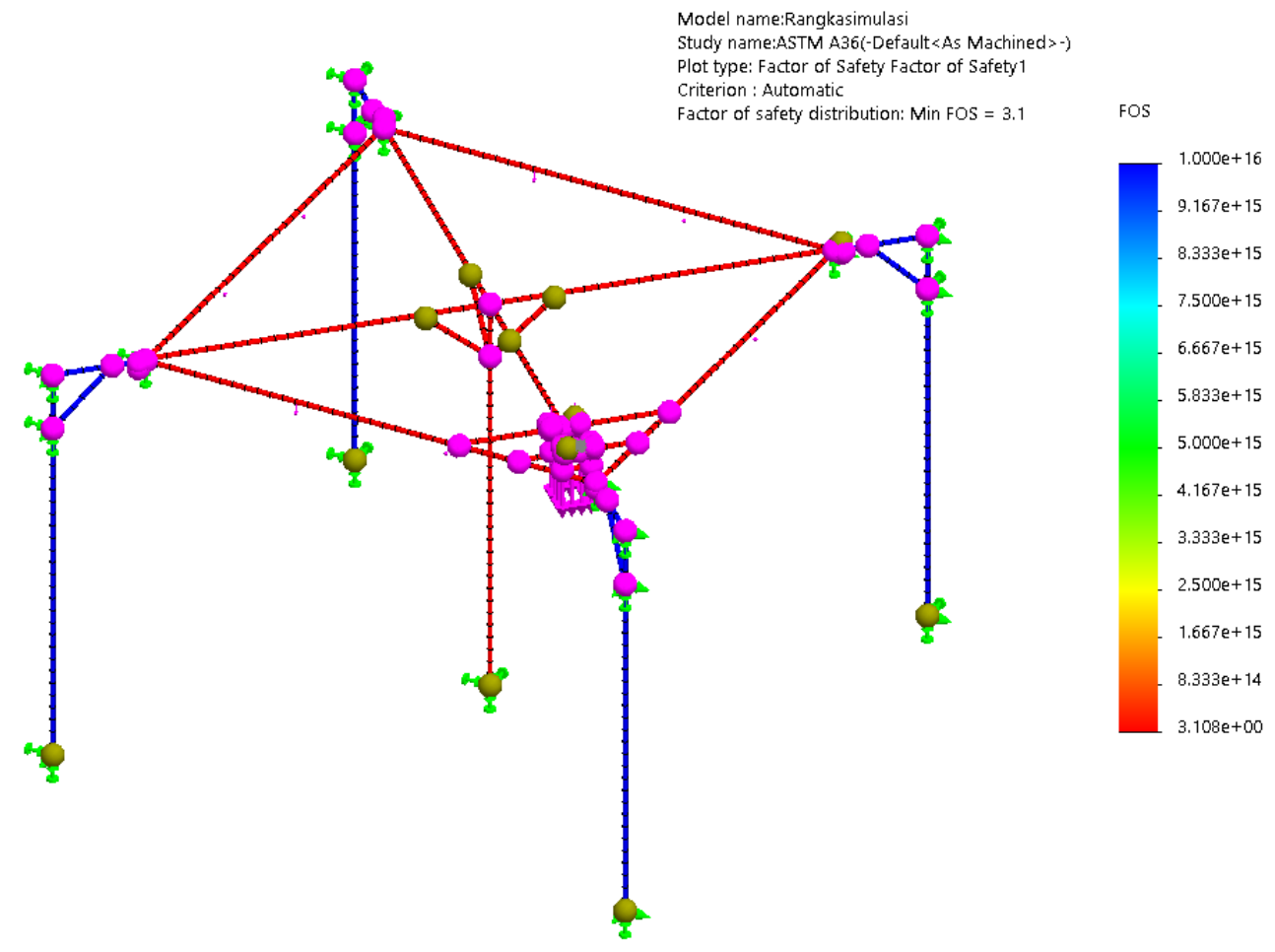

Gambar 9. Analisa Factor of Safety 
Suharto dkk./Jurnal Rekayasa Mesin p-ISSN: 1411-6863, e-ISSN: 2540-7678

Vol.16|No.3|425-436|Desember|2021

Faktor keamanan kurang dari 1 menunjukkan kegagalan permanen dari sebuah desain kerangka sebuah mesin. Pada gambar analisa Safety Factor diatas menunjukan hasil bahwa material besi hollow $60 \mathrm{~mm}$ x 40 mm x 2,4 mm ASTM A36 Steel cukup kuat untuk menahan jumlah beban beban $1000 \mathrm{~N}$ dengan faktor keamanan 3,1. Adapun rangka alat pengering gitar ini diperuntukkan membawa beban dinamis, maka Faktor keamanan dari hasil simulasi adalah AMAN karena Nilai faktor keamanan 3,1. Dan berada dalam nalai FOS dari beban statis. Berikut keterangan beban statis (1,25-2), beban dinamis (2-3) maupun beban kejut (3-5) [12].

\subsection{Pengujian}

Pengujian untuk menguji kinerja mesin ini dibagi menjadi dua, yaitu pengujian kinerja overhead chain conveyor terhadap beban angkut yang variatif, dan pengujian kinerja overhead chain conveyor terhadap proses finishing pengeringan gitar.

\subsubsection{Pengujian massa angkut}

Pengukuran massa, voltase, kuat arus dan Rpm dilakukan untuk mengetahui kekuatan atau daya listrik dalam menggerakkan massanya [11]. Pada pengujian massa angkut variatif antara lain massa muatan sebesar $3 \mathrm{~kg}$ tiap gitar dengan beberapa klasifikasi beban antara lain $0 \mathrm{~kg}$ atau tanpa muatan, $6 \mathrm{~kg}, 12 \mathrm{~kg}, 18 \mathrm{~kg}, 24 \mathrm{~kg}, 30 \mathrm{~kg}, 36 \mathrm{~kg}, 42 \mathrm{~kg}, 48$ $\mathrm{kg}, 54 \mathrm{~kg}, 60 \mathrm{~kg}$. Untuk kecepatan gerak linier maksimum (vmaks) sebesar 0,3 m/s dan kecepatan gerak linier minimum (vmin) sebesar $0,26 \mathrm{~m} / \mathrm{s}$. Hasil pengujian kinerja overhead chain conveyor berdasarkan beban angkut variatif mendapatkan hasil pengukuran tegangan, kuat arus, dan rpm.

Tabel 1. Hasil pengujian massa angkut variatif

\begin{tabular}{cccc}
\hline Massa $[\mathrm{Kg}]$ & Voltase [Volt] & Kuat arus [A] & Rpm \\
\hline 0 & 103 & 1,23 & 21 \\
6 & 106 & 1,21 & 20,8 \\
12 & 108 & 1,2 & 20,7 \\
18 & 109 & 1,19 & 20,7 \\
24 & 111 & 1,17 & 20,5 \\
30 & 113 & 1,17 & 20,4 \\
36 & 116 & 1,15 & 20,4 \\
42 & 118 & 1,14 & 20,3 \\
48 & 122 & 1,12 & 20,1 \\
54 & 124 & 1,11 & 19,9 \\
60 & 125 & 1,11 & 19,9 \\
\hline
\end{tabular}

Tabel 2. Perhitungan Hubungan Tegangan, Kuat arus dan Daya

\begin{tabular}{|c|c|c|c|}
\hline Massa $[\mathrm{Kg}]$ & Voltase [Volt] & Kuat Arus [A] & Daya [Watt] \\
\hline 0 & 103 & 1,23 & 126,7 \\
\hline 6 & 106 & 1,21 & 128,3 \\
\hline 12 & 108 & 1,2 & 129,6 \\
\hline 18 & 109 & 1,19 & 129,7 \\
\hline 24 & 111 & 1,17 & 129,9 \\
\hline 30 & 113 & 1,17 & 132,2 \\
\hline 36 & 116 & 1,15 & 133,4 \\
\hline 42 & 118 & 1,14 & 134,5 \\
\hline 48 & 122 & 1,12 & 136,6 \\
\hline 54 & 124 & 1,11 & 137,6 \\
\hline 60 & 125 & 1,11 & 138,8 \\
\hline
\end{tabular}

Pada pengujian ini, menggunakan kecepatan minimum (vmin) sebesar 0,26 m/s. Hasil dari proses pengujian ditampilkan pada Tabel 1. Pada pengujian alat pengeringan gitar berdasarkan massa angkut variatif, diperoleh perhitungan 
Suharto dkk./Jurnal Rekayasa Mesin p-ISSN: 1411-6863, e-ISSN: 2540-7678

Vol.16|No.3|425-436|Desember|2021

daya untuk memutar massa angkut yang variatif. Dengan hasil ini didapatkan grafik hubungan daya, tegangan dan kuat arus, Tabel 2.

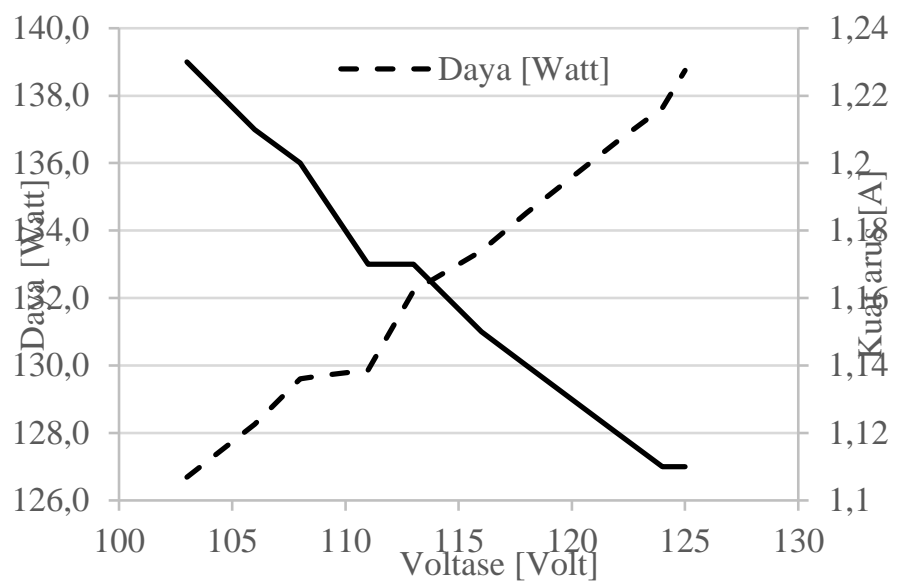

Gambar 10. Hubungan daya dan kuat arus Pada saat alat pengeringan sedang beroperasi

Gambar 10 menunjukan bahwa pengujian ini adanya hubungan yang koreponden antara voltase, kuat arus, dan daya. Kenaikan variabel pada tegangan mengakibatkan kenaikan variabel daya dan kuat arus. Dengan hal ini, variabel tegangan menunjukkan poin utama dalam pengujian massa angkut, akan tetapi kenaikan tegangan pada pengujian diatas mengalami kenaikan variabel yang inkonsisten Nilai inkonsisten ini, dikarenakan massa gitar yang tidak seragam secara tepat karena bentuk dan model gitar yang berbeda, selain hal ini juga dipengaruhi dari karakteristik gitar secara spesifik, pada prinsipnya seperti massa konstruksi kayu tiap gitar. Pada grafik diatas hubungan antara voltase, kuat arus dan daya berhubungan berbanding lurus. Dengan hal ini, bisa dikatakan akan ada korelasi yang saling terhubung satu dengan yang lainnya. Semakin besar tegangan (Volt) maka akan akan bertambah pula kuat arus (Ampere) dan daya (Watt).

\subsubsection{Pengujian pengeringan}

Pada pengujian hasil akhir pengeringan gitar antara lain suhu ruangan dan kadar air pada permukaan gitar setelah proses pengecatan. Dalam hal ini perbandingan antara proses pengeringan gitar secara manual dan proses pengeringan gitar secara rotate dengan kecepatan gerak linier (v) sebesar 0,26 m/s. Dari pengujian yang dilakukan maka diperoleh data untuk kemudian ditampilkan dalam tabel dan grafik. Hasil pengujian kinerja overhead chain conveyor berdasarkan proses pengeringan gitar diluar ruangan dan dalam ruangan mendapatkan nilai kadar air $[14,15]$ pada permukaan gitar dan lama waktu pengeringan gitar. Hasil dari proses pengujian ditampilkan pada Tabel 3.

Tabel 3. Pengujian kinerja overhead chain conveyor proses pengeringan

\begin{tabular}{|c|c|c|c|c|c|}
\hline \multicolumn{6}{|c|}{ Pengujian Kinerja Berdasarkan Proses Finishing (Pengeringan) } \\
\hline \multirow{2}{*}{ Menit ke- } & \multirow{2}{*}{ Pengujian ke- } & \multicolumn{2}{|c|}{ Luar Ruangan } & \multicolumn{2}{|c|}{ Dalam Ruangan } \\
\hline & & Waktu (Menit) & Kadar Air (\%) & Waktu (Menit) & Kadar Air (\%) \\
\hline 0 & 1 & 18,34 & 14,1 & 18,35 & 14,4 \\
\hline 5 & 2 & 18,39 & 10,3 & 18,4 & 9,2 \\
\hline 10 & 3 & 18,44 & 8,7 & 18,45 & 6,4 \\
\hline 15 & 4 & 18,49 & 8 & 18,5 & 5,3 \\
\hline 20 & 5 & 18,54 & 7,1 & 18,55 & 4,4 \\
\hline 25 & 6 & 18,59 & 6,5 & 19 & 3,3 \\
\hline 30 & 7 & 19,04 & 5,8 & 19,05 & 3 \\
\hline
\end{tabular}


Suharto dkk./Jurnal Rekayasa Mesin p-ISSN: 1411-6863, e-ISSN: 2540-7678

Vol.16|No.3|425-436|Desember|2021

Pengujian Kinerja Berdasarkan Proses Finishing (Pengeringan)

\begin{tabular}{cccccc}
\hline \multirow{2}{*}{ Menit ke- } & \multirow{2}{*}{ Pengujian ke- } & \multicolumn{2}{c}{ Luar Ruangan } & \multicolumn{2}{c}{ Dalam Ruangan } \\
\cline { 3 - 6 } & & Waktu (Menit) & Kadar Air (\%) & Waktu (Menit) & Kadar Air $(\%)$ \\
\hline 35 & 9 & 19,09 & 4,1 & 19,1 & 2,5 \\
40 & 10 & 19,14 & 3,5 & 19,15 & 0 \\
45 & 11 & 19,19 & 3,1 & 19,2 & 0 \\
50 & 12 & 19,24 & 2,5 & 19,25 & 0 \\
55 & 13 & 19,29 & 2,5 & 19,3 & 0 \\
60 & 19,34 & 0 & 19,35 & 0 \\
\hline
\end{tabular}

Pada pengujian alat pengeringan gitar berdasarkan proses pengeringan gitar dan lama waktu proses manual (sebelum adanya alat overhead chain conveyor) dan proses rotate (setelah adanya alat overhead chain conveyor), diperoleh hasil waktu dan kadar air tiap jeda waktu (range) selama 5 menit. Kemudian dari pengujian tersebut dibuat grafik seperti pada Gambar 11.

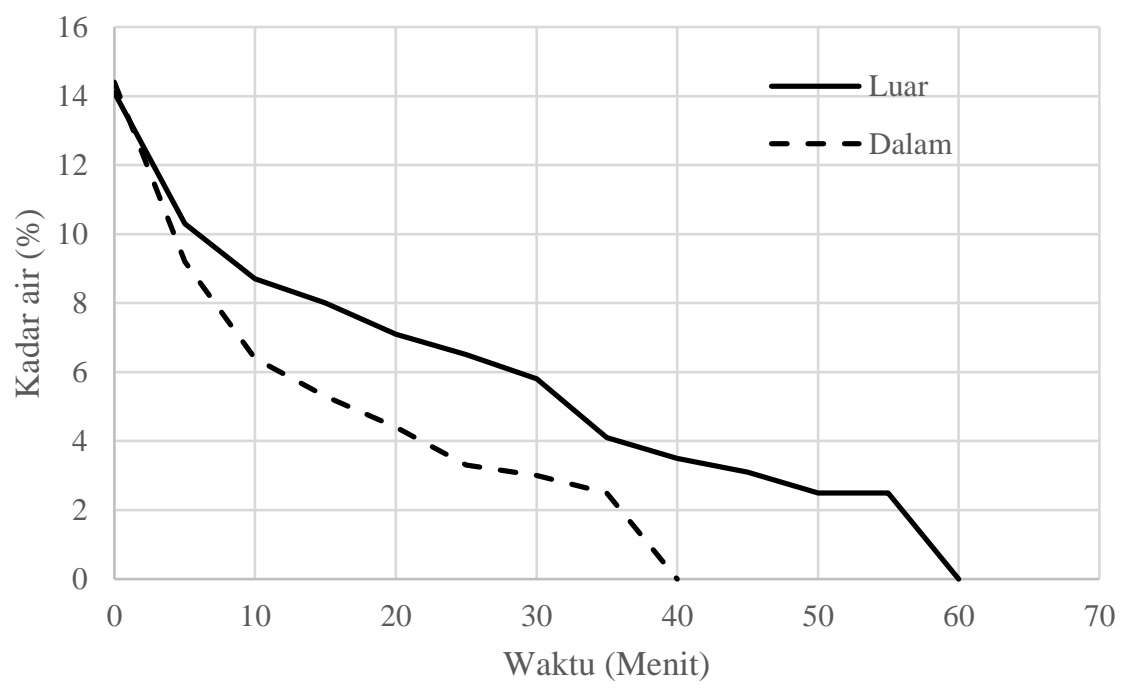

Gambar 11. Grafik lama waktu pengeringan terhadap presentase kadar air

Gambar 11 menunjukkan adanya perbedaan variabel waktu yang cukup signifikan mengingat efisiensi waktu yang didapat dalam pengujian ini. Dengan hal ini, variabel kadar air menunjukkan poin utama dalam proses pengeringan gitar, ditandai kadar air pada proses pengeringan gitar yang semakin berkurang dengan perlahan. Lama waktu pengeringan gitar dengan proses manual menempuh waktu 60 menit untuk hasil yang benar-benar kering, sedangkan pada proses rotate menempuh waktu 40 menit. Selain hal itu, perbedaan hasil permukaan gitar antara kedua mengalami perbedaan, seperti Gambar 12 .

Perbedaan kedua gambar diatas yakni adanya perbedaan perlakuaan pengeringan, dan hasil akhir pada gitar setelah pengeringan. Gambar diatas terdapat perbedaan dari dua cara pengeringan. Pertama, dengan proses manual yang hanya dilakukan dengan cara manual di luar ruangan dan efek akhir terdapat debu di permukaan gitar sesuai Gambar 12 (a), sedangkan pada proses rotate dilakukan dengan gerak rotasi secara berulang dengan tujuan keseragaman proses pengeringan gitar di semua bidang permukaan gitar (setelah pengecatan), sesuai Gambar 12 (b). 
Suharto dkk./Jurnal Rekayasa Mesin p-ISSN: 1411-6863, e-ISSN: 2540-7678

Vol.16|No.3|425-436|Desember|2021

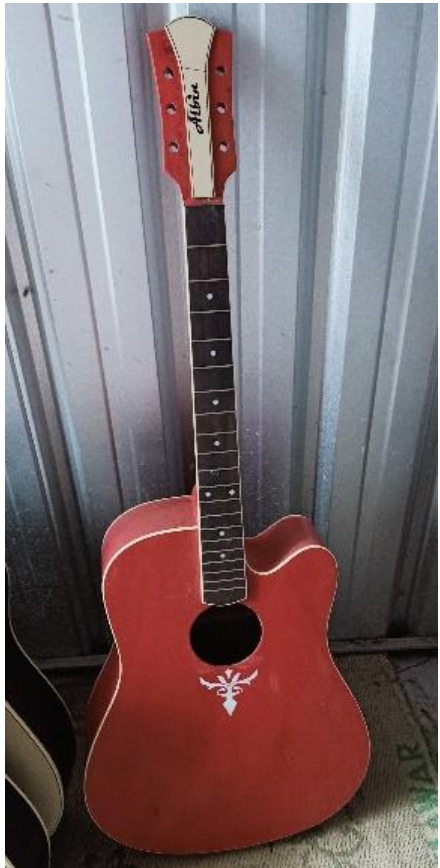

(a)

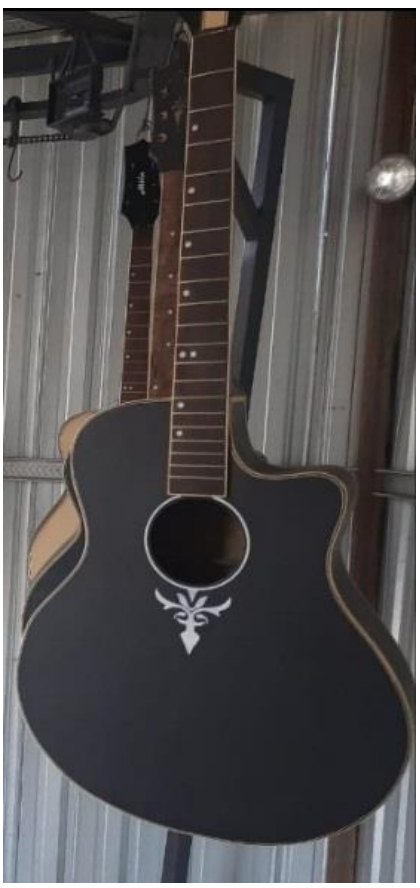

(b)

Gambar 12. (a) Proses pengeringan manual dan (b) proses pengeringan sekarang

\section{Kesimpulan}

Kesimpulan yang dapat diambil dari keseluruhan proses dalam perancangan dan pengujian rancang bangun alat pengeringan gitar dengan sistem overhead chain conveyor model forward-reverse yaitu menghasilkan rancangan desain dan model alat bantu pengeringan gitar dengan sistem overhead chain conveyor dengan penggerak motor listrik $1 \mathrm{HP}$, dimensi alat $2770 \mathrm{~mm}$ x $2770 \mathrm{~mm}$ x $2400 \mathrm{~m}$. Perbandingan antara yield strength bahan dan tegangan bengkok maksimum yang terjadi ( $\sigma \mathrm{bmaks}$ ) adalah yield strength $>$ obmaks, $290 \mathrm{~N} / \mathrm{mm} 2>24,07 \mathrm{~N} / \mathrm{mm} 2$, kesimpulan bahwa YS $>$ Tegangan VM, maka tegangan von mises yang dihasilkan masih AMAN. Mengetahui daya yang dapat memutar gitar, dengan beban penuh $60 \mathrm{~kg}$ membutuhkan daya sebesar 138,89 Watt, sedangkan saat beban minimum (tanpa beban) membutuhkan daya sebesar 126,7 Watt. Menghasilkan alat bantu pengeringan gitar yang mampu memangkas waktu 20 menit lebih awal dibanding dengan proses pengeringan manual..

\section{Daftar Pustaka}

[1] https://www.merdeka.com/jateng/mengunjungi-kampung-gitar-di-sukoharjo-surganya-pecinta-alat-musikpetik.html diakses pada 07-11-2021.

[2] https://www.tribunnews.com/regional/2018/02/09/desa-mancasan-sukoharjo-kampung-pengrajin-gitar-kelasinternasional diakses pada 07-11-2021

[3] Al-Bahra Bin Ladjamudin, 2005, Analisis dan Desain Sistem Informasi, Graha Ilmu, Yogyakarta

[4] Shigley’s. 2011. Mechanical Engineering Design (Ninth Edition). New York: McGraw-Hill Companies.

[5] Khurmi.R.S \& Gupta J.K. 2005. A Textbook Of Machine Design (SI Units). New Delhi : Eurasia Publishing House (PVT.) Ltd.

[6] Mott, R. L., 2004, Machine Elements In Mechanical Design, Fouth Edition Perason Education : New Jersey.

[7] Sato, G. Takeshi dan N. Sugiarto Hartanto. 1986. Menggambar Mesin Menurut Standar ISO. Jakarta: Pradnya Paramita. 
[8] Sularso, Kiyokatsu Suga. 1997. Dasar Perencanaan dan Pemilihan Mesin. Jakarta: Pradnya Paramita.

[9] Fauzi, Muhammad Nur. 2018. Laporan Tugas Akhir Sistem Transmisi Rantai Pada Purwarupa roda lincah UNS. Surakarta : Universitas Sebelas Maret.

[10] Lufhianto, Andrian. 2017. Perencanaan Ulang Sistem Transmisi Rantai Mobil Nogogeni EVO 3. Surabaya : Institut Teknologi Sepuluh Nopember.

[11] Raharja, Afifaruq Etwin. 2020. Perancangan Bearing pada mesin vertical centrifugal casting. Surakarta : Universitas Sebelas Maret.

[12] V. Dobrovolsky, 1978

[13] Saptono, Hery., dkk. Analisa daya dan kontrol kecepatan motor pada alat bantu las rotary positioner table. Bogor: Universitas Ibnu Khaldun.

[14] Sri Nugroho Marsoem, Vendy Eko Prasetyo, Joko Sulistyo, Sudaryono, Ganis Lukmandaru, 2014, Studi Mutu Kayu Jati di hutan Rakyat Gunungkiful III: Sifat Fisika Kayu, Jurnal Ilmu Kehutanan, Vol. 8, No. 2, hal. 75-88.

[15] Winingsih, Puji Hariati. 2017 "Eksperimen gaya gesek untuk menguji nilai koefisien gesekan statis kayu pada kayu dengan program matlab" Jurnal Science Tech Vol. 3, No. 2, Agustus Program Studi Pendidikan Fisika: UST Yogyakarta. 